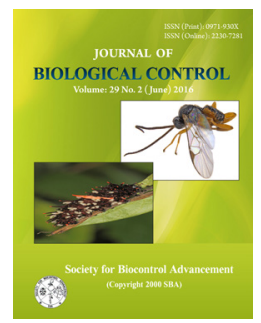

\title{
Parasitoid, Aenasius arizonensis (Girault) (Hymenoptera: Encyrtidae): Its biology, morphometrics, host stage preference and use in biological control
}

\author{
T. M. AGA, V. J. TAMBE, V. S. NAGRARE ${ }^{1 *}$ and BHAUSAHEB NAIKWADI ${ }^{1}$ \\ College of Agriculture, Maharaj Bag, Amravati Road, Nagpur-440 001, India. \\ ${ }^{1}$ Central Institute for Cotton Research (CICR), P. B. No. 2, Shankar Nagar P. O., Nagpur- 440 010, India. \\ Corresponding author Email: vs.nagrare@gmail.com
}

\begin{abstract}
Aenasius arizonensis (Girault) (=Aenasius bambawalei Hayat) (Hymenoptera: Encyrtidae), a solitary endoparasitoid of Phenacoccus solenopsis Tinsley, is a major invasive pest in several cotton growing countries around the globe. It has been recorded as an effective natural enemy of $P$. solenopsis. The biological characteristics of parasitoid were studied on $P$. solenopsis under laboratory conditions. The mean duration of development of $A$. arizonensis from oviposition to mummy formation was $5.9 \pm 0.31$ days for both male and female, while from mummy formation to adult emergence was $5.9 \pm 0.31$ and $7.3 \pm 0.3$ for male and female, respectively. The mean developmental period of male and female was $12.2 \pm 0.33$ and $14.2 \pm 0.37$ days, respectively. Males were short lived (16.3 \pm 1.41 days) as compared to females $(26.2 \pm 1.72$ days). Female started ovipositing on the day of emergence. The mean pre-oviposion, oviposition and post-oviposition periods were $<1,23.1 \pm 1.66$ and $3.1 \pm 0.55$ days, respectively. Mean daily and total fecundity in terms of number of parasitized host per female was $4.24 \pm 0.2$ and 100.5 \pm 11.57 , respectively. Sex ratio was skewed towards female and recorded as 1:2. Maximum percentage of parasitization occurred in adult host stage i.e. $90 \%$ followed by $3^{\text {rd }}, 2^{\text {nd }}$, and $1^{\text {st }}$ instar nymph with $73.33 \%, 33.33 \%$ and 0 per cent, respectively. Among the three nymphal stages 3rd instar nymph was the most suitable stage for mass multiplication of parasitoid. Its successful utilization in mealybug management can be optimized by multiplying at this stage of host in the laboratory and thereafter inoculative release into the field. This report provides a detailed diagnostic description of $A$. arizonensis with illustration to facilitate easy identification \& morphological differences between male \& female along with the morphometric measurements of pupa \& mummy.
\end{abstract}

KEY WORDS: Aenasius arizonensis, biology, morphometrics, host stage preference, biological control

(Article chronicle: Received: 23-05-2016 Revised: 01-06-2016; Accepted: 18-06-2016)

\section{INTRODUCTION}

The solenopsis mealybug, Phenacoccus solenopsis Tinsley (Pseudococcidae: Hemiptera) has been reported to have invaded and colonized in more than 23 countries across all inhabited continents of the globe, since 1991 (Ahmed et al., 2015). It has the potential to invade worldwide and establish populations in more than 100 countries, mainly in tropical and subtropical zones as illustrated by CLIMEX prediction models (Wang et al., 2010). The pest feeds on wide range of $>202$ host plant species that include field crops, ornamentals, trees and vegetables (CABI, 2015) and listed as a serious pest due to its detrimental effect on economically important crops, especially cotton. It has become a major pest in Asian countries where world's approximately $75 \%$ of the cotton is being produced in the region.

A new parasitoid Aenasius arizonensis (Girault) (=Aenasius bambawalei Hayat) (Hymenoptera: Encyrtidae) is described for the first time from India (Hayat, 2009). It is a solitary endoparasitoid and the only dominant aggressive parasitoid on $P$. solenopsis under natural conditions reported until now. Biocontrol of P. solenopsis by A. arizonensis is the most successful example of biological control of mealybug by this hymenopterous parasitoid. As high as 37.6 to 72.3 per cent parasitization of mealybugs by this parasitoid, has been recorded from different field surveys across India (Ram et al., 2009). Several researchers have reported its parasitization potential with varying degrees in India (Ram et al., 2009; Nagrare et al., 2011; Prasad et al., 2011; Sankar et al., 2011), Pakistan (Mahmood, 2008; Ashfaq 2010; Bodlah, 2010; Arif et al., 2011), China (Chen et al., 2010), Australia (Spargo et al., 2013) and Iran (Fallahzadeh et al., 2014) on P. solenopsis. Genetic analysis provided by Ahmed and co-workers (2015) indicated that P. solenopsis has a close relationship with $A$. arizonensis, provides preliminary evidence of a congruent spread of this mealybug and its parasitoids. 
Biological control agents of insect pests play a key role in keeping the pest populations below economic injury level. Both natural and applied biological control tactics are important in successful management of pest populations (Ignacimuthu, 2002). Biological control has been an important component in pest management programs around the globe for the last several decades. However, wide use of synthetic chemicals have deleterious effect on the population of biological control agents. Biological control has a tremendous value especially in the context of environmental protection as as well as sustainable pest management approach (Ignacimuthu and Jayaraj, 2003).

Reproductive success of biological control agents especially of parasitoids mainly depends on the host stage parasitized (Sequeira and Mackauer, 1993), body size (Liu, 1985; Lampson et al., 1996) and progeny sex ratio (Napoleon and King, 1999) and egg load (Liu 1985, Visser 1994, Mills and Kuhlmanm, 2000). In majority of the cases parasitoid prefer particular host stage as compared to other stages. Host size, which is considered as host quality index, has significant influence on the egg laying by parasitoid (Liu, 1985, Charnov 1981)). Several studies indicated that parasitism can impact the development of fecundity and population growth of the hosts (Lin and Ives, 2003; He et al., 2005). Keeping in view of importance of $A$. arizonensis as a potential biological control agent, the present investigation was undertaken with a objective to study biology for determining developmental time, sex ratio, morphometrics and host stage preference on different life stages of its host P. solenopsis.

\section{MATERIALS AND METHODS}

The laboratory experiment on biology, morphometrics and host stage preference of $A$. arizonensis was carried out at Insectary and Biocontrol laboratory of Central Institute for Cotton Research, Nagpur. The culture of the host (P. solenopsis) as well as parasitoid (mummies) were collected from North-East part of Nagpur district of Maharashtra state and Chhindwara district of Madhya Pradesh.

\section{Rearing of host insect Phenococcus solenopsis and Ae- nasius arizonensis culture in laboratory}

Phenacoccus solenopsis females and the newly hatched first instar nymphs from mother culture were released on potato sprouts (Solanum tuberosum) grown in plastic trays (tubs) containing moist soil and was kept under laboratory conditions of $27^{\circ} \mathrm{C}$ temperature and $50-60 \%$ RH. A. arizonensis emerging from mummies were used for establishment of mother cultures. A. arizonensis were released singly in glass vials plugged with cotton and pro- vided with honey and water as a food source and multiplied on $P$. solenopsis for experimental use.

\section{Biological observations}

For studying different biological parameters 20 individuals of $P$. solenopsis ( ${ }^{\text {rd }}$ instar) were released on sprouted potatoes in a plastic jar along with freshly emerged pair of parasitoid for 24 hours duration. Honey $(50 \%)$ was provided as a source of food by making cotton swab tied with thread and kept hanging in jar for parasitoid (Poorani et al., 2009). After 24 hours, A. arizonensis were shifted to a similar new set of 20 mealybugs in a plastic jar. The procedure was repeated daily until the female parasitoid was dead (Vijaya et al., 2011). The biological observations were taken on the parameters like mean developmental period from oviposition to mummy formation, mummy formation to adult emergence, developmental period of male and female, total life period of male and female, mean daily and total fecundity in terms of parasitized host and male-female ratio.

\section{Morphometric observations}

Different visual stages of parasitoid were critically examined under stereoscopic microscope for their color and shape. Morphometric observations were taken with the help of stereoscopic microscope with camera attachment by using Leica Application Suite (LAS) software on dimensions of $A$. arizonenesis under study.

\section{Host stage preference}

Thirty mealybug of each instar were released on sprouted potatoes in different jars and exposed separately to 5 pairs of parasitoid (emerged from $3^{\text {rd }}$ instar nymphs of mealybugs) for $48 \mathrm{hrs}$ (Solangi and Mahmood, 2011). This experiment was repeated 5 times. The exposed mealybugs were examined up to 10 days to see if there was any mummy formation. The total mummified bodies were counted and per cent mummy formation in each instar was calculated.

\section{Statistical analysis}

The data, so obtained, on the various aspects were subjected to statistical analysis using Microsoft Office Excel Software (Microsoft Corp., Redmond, WA, USA) to get mean values of observations along with S.E. (m). Parasitization percentage and sex ratio was also calculated from the available data on number of parasitized host per female.

\section{RESULTS AND DISCUSSION}

\section{Biological attributes}

The results of study revealed that mean duration from 
Table 1. Biological attributes of Aenasius arizonensis

\begin{tabular}{|c|c|c|c|c|c|}
\hline Sr. No. & Biological characteristic & & Number Observed & Mean \pm S.E. $(\mathrm{m})$ & Range \\
\hline 1 & Oviposition to mummy formation (days) & & 10 & $5.9 \pm 0.31$ & $5-8$ \\
\hline \multirow[t]{2}{*}{2} & Adult emergence after mummy formation (days) & Male & 10 & $5.9 \pm 0.31$ & $4-7$ \\
\hline & & Female & 10 & $7.3 \pm 0.30$ & $6-9$ \\
\hline \multirow[t]{2}{*}{3} & Developmental period (days) & Male & 10 & $12.2 \pm 0.33$ & $10-13$ \\
\hline & & Female & 10 & $14.2 \pm 0.37$ & $13-16$ \\
\hline 4 & Pre-oviposition period (days) & & 10 & $<1$ & $<1$ \\
\hline 5 & Oviposition period (days) & & 10 & $23.1 \pm 1.66$ & $13-20$ \\
\hline 6 & Post-oviposition period (days) & & 10 & $3.1 \pm 0.55$ & $0-5$ \\
\hline 7 & Daily fecundity (No. of parasitized host/female/da & & 10 & $4.24 \pm 0.20$ & $2-19$ \\
\hline 8 & Total fecundity (No. of parasitized hosts/female) & & 10 & $100.5 \pm 11.57$ & $46-169$ \\
\hline 9 & Male longevity (days) & & 10 & $16.3 \pm 1.41$ & $8-24$ \\
\hline 10 & Female longevity (days) & & 10 & $26.2 \pm 1.72$ & $18-34$ \\
\hline 11 & Sex ratio of progeny (Male:female) & & 10 & $\begin{array}{l}\text { Male : female rat } \\
(1: 1.97)=(1: 2)\end{array}$ & \\
\hline
\end{tabular}

oviposition to mummification was $5.9 \pm 0.31$ days. The period ranged from 5-8 days for the total number of observations recorded. Mean developmental period between mummy formation and adult emergence was $5.9 \pm 0.31$ and $7.3 \pm 0.3$ for male and female, respectively. Developmental period of male varied from 4-7 days and for female from 6-9 days. The mean developmental period was observed to be $12.2 \pm 0.33$ and $14.2 \pm 0.37$ days for male and female, respectively. The developmental period ranged from 10-13 for male and 13-16 days for female. Longevity of male was $16.3 \pm 1.41$ days and thereof female $26.2 \pm 1.72$ days. The total longevity ranged between 8-24 days and 18-34 days for male and female, respectively. Mean daily and total fecundity in terms of number of parasitized host per female was $4.24 \pm 0.2$ and $100.5 \pm 11.57$, respectively. In its whole life, female parasitized $46-169$ mealybugs. The number of parasitized mealybugs per day ranged from 2-19. The total number of adult emerged were 98 constituting 94.33 per cent out of which 33 were male and 65 were female. Thus male: female ratio in the progeny was recorded 1:1.97 (i.e. 1:2) (Table 1).

\section{Morphometric observations Adult male and female}

Male and female emerged out by cutting a circular small hole on mummies after completion of pupal period. Both sexes could easily be identified by their size and antennae. Adult female was found distinctively larger than male. The males differed from female by their large and curved banana shaped antennal clava. Head of male was somewhat dumb-bell shaped, small and attached narrowly with the thorax whereas in female it was somewhat oval shaped, slightly larger than thorax and broadly attached with it. Though adults of both sexes were blackish in color, the female body was shiny black in color with large thimble like punctures on head. Whereas male was fairly dull black in color.

\section{Dimensions of adult male}

The mean length of forelegs was $1.08 \pm 0.03 \mathrm{~mm}$, varied from $0.98-1.29 \mathrm{~mm}$. The mean length of middle leg was $1.15 \pm 0.04 \mathrm{~mm}$ with a range from $1-1.49 \mathrm{~mm}$ and the mean length of hind leg length was $1.21 \pm 0.05 \mathrm{~mm}$ ranged from $1.09-1.51 \mathrm{~mm}$. The length of antenna varied from $0.67-0.95 \mathrm{~mm}$ with mean $0.76 \pm 0.03 \mathrm{~mm}$. Wings were transparent and membranous. The fore wing length varied from $0.66-1.20 \mathrm{~mm}$ with an average $0.84 \pm 0.06 \mathrm{~mm}$. The breadth of fore wing was $0.32 \pm 0.04 \mathrm{~mm}$ confined in 0.23 - 0.60. The hind wing length varied from $0.59-1.01 \mathrm{~mm}$ with mean $0.77 \pm 0.04 \mathrm{~mm}$ and breadth varied from 0.22 $0.30 \mathrm{~mm}$ with mean $0.27 \pm 0.03 \mathrm{~mm}$. The shortest diameter of eye varied from $0.23-0.36 \mathrm{~mm}$ with an average 0.29 $\pm 0.01 \mathrm{~mm}$ and longest diameter varied from $0.33-0.42 \mathrm{~mm}$ with an average $0.39 \pm 0.001 \mathrm{~mm}$ (Table 2).

\section{Dimensions of adult female}

The mean length of adult female was $1.83 \pm 0.08 \mathrm{~mm}$ with a range from $1.47-2.15 \mathrm{~mm}$ whereas breadth 0.78 $\pm 0.05 \mathrm{~mm}$ ranged from $0.49-1.00 \mathrm{~mm}$. The head breadth varied from $0.55-1.11 \mathrm{~mm}$ with an average $0.82 \pm 0.5 \mathrm{~mm}$. The length of forelegs varied from $1.27-1.68 \mathrm{~mm}$ with an average $1.35 \pm 0.04 \mathrm{~mm}$. Length of middle leg varied from $1.62-1.98 \mathrm{~mm}$ with an average $1.55 \pm 0.04 \mathrm{~mm}$ and the hind leg length varied from $1.88-2.32 \mathrm{~mm}$ with an average $1.89 \pm 0.05 \mathrm{~mm}$. The length of antenna varied from $0.68-1.18 \mathrm{~mm}$ with an average $0.93 \pm 0.05 \mathrm{~mm}$. The wings were membranous; however the basal portion of wings of female was blackish in colour. The fore wing length varied from $1.24-1.62 \mathrm{~mm}$ with an average $1.48 \pm 0.04 \mathrm{~mm}$. The breadth of fore wing varied from $0.55-0.68 \mathrm{~mm}$ with an 
Table 2. Morphometric measurements of Aenasius arizonensis

\begin{tabular}{|c|c|c|c|c|c|c|}
\hline \multirow[t]{2}{*}{ Sr. No. } & \multirow[t]{2}{*}{ Morphological character } & \multirow[t]{2}{*}{ Number observed } & \multicolumn{2}{|c|}{ Male (mm) } & \multicolumn{2}{|c|}{ Female (mm) } \\
\hline & & & Mean \pm S.E.(m) & Range & Mean \pm S.E.(m) & Range \\
\hline 1 & Total length & 10 & $1.38 \pm 0.06$ & $0.99-1.68$ & $1.83 \pm 0.08$ & $1.47-2.15$ \\
\hline 2 & Total breadth & 10 & $0.54 \pm 0.03$ & $0.43-0.66$ & $0.78 \pm 0.05$ & $0.49-1.00$ \\
\hline 3 & Head breadth & 10 & $0.54 \pm 0.03$ & $0.44-0.67$ & $0.82 \pm 0.05$ & $0.55-1.11$ \\
\hline 5 & Length (foreleg) & 10 & $1.08 \pm 0.03$ & $0.98-1.29$ & $1.35 \pm 0.04$ & $1.27-1.68$ \\
\hline 6 & Length (middle leg) & 10 & $1.15 \pm 0.04$ & $1.00-1.49$ & $1.55 \pm 0.04$ & $1.62-1.98$ \\
\hline 7 & Length (hind leg) & 10 & $1.21 \pm 0.05$ & $1.09-1.51$ & $1.89 \pm 0.05$ & $1.88-2.32$ \\
\hline 8 & length of antenna & 10 & $0.76 \pm 0.03$ & $0.67-0.95$ & $0.93 \pm 0.05$ & $0.68-1.18$ \\
\hline 9 & Length of fore wing & 10 & $0.84 \pm 0.06$ & $0.66-1.20$ & $1.48 \pm 0.04$ & $1.24-1.62$ \\
\hline 10 & Breadth of fore wing & 10 & $0.32 \pm 0.04$ & $0.23-0.60$ & $0.65 \pm 0.01$ & $0.55-0.68$ \\
\hline 11 & Length of hind wing & 10 & $0.77 \pm 0.04$ & $0.59-1.01$ & $0.96 \pm 0.01$ & $0.89-1.00$ \\
\hline 12 & Breadth of hind wing & 10 & $0.27 \pm 0.03$ & $0.22-0.30$ & $0.43 \pm 0.01$ & $0.40-0.47$ \\
\hline 13 & Shortest diameter eye & 10 & $0.29 \pm 0.01$ & $0.23-0.36$ & $0.48 \pm 0.00$ & $0.45-0.50$ \\
\hline \multirow[t]{2}{*}{14} & longest diameter eye & 10 & $0.39 \pm 0.01$ & $0.33-0.42$ & $0.59 \pm 0.01$ & $0.57-0.62$ \\
\hline & & & \multicolumn{2}{|l|}{ Pupa } & \multicolumn{2}{|c|}{ Mummy } \\
\hline 15 & Length & 10 & $1.29 \pm 0.03$ & $1.19-1.53$ & $3.74 \pm 0.13$ & $3.37-4.43$ \\
\hline 16 & Breadth & 10 & $0.61 \pm 0.02$ & $0.53-0.71$ & $2.05 \pm 0.13$ & $1.19-2.56$ \\
\hline
\end{tabular}

average $0.65 \pm 0.01 \mathrm{~mm}$. The hind wing length varied from $0.89-1.00 \mathrm{~mm}$ with an average $0.96 \pm 0.01 \mathrm{~mm}$ and breadth from $0.40-0.47 \mathrm{~mm}$ with an average $0.43 \pm 0.01 \mathrm{~mm}$. The shortest diameter of eye varied from $0.45-0.50 \mathrm{~mm}$ with an average $0.48 \pm 0.003 \mathrm{~mm}$ and longest diameter varied from $0.57-0.62 \mathrm{~mm}$ with an average $0.59 \pm 0.01 \mathrm{~mm}$ (Table 2).

\section{Mummy and pupa}

The mummy was barrel shaped and dark reddish brown in color. The length of mummy varied from 3.37- $4.45 \mathrm{~mm}$ with an average of $3.74 \pm 0.13 \mathrm{~mm}$. Breadth of mummy varied from $1.19-2.56 \mathrm{~mm}$ with an average of $2.05 \pm 0.13$ $\mathrm{mm}$. The pupa was obtained by dissecting mummy. It was typical execrate shiny pale brown colored when observed under stereoscopic microscope. The mean length of pupa was $1.29 \pm 0.03 \mathrm{~mm}$ and this was varied from $1.19-1.53 \mathrm{~mm}$ while breadth of pupa varied from $0.53-0.71 \mathrm{~mm}$ with an average $0.61 \pm 0.02 \mathrm{~mm}$ (Table 2). All the morphometric measurements of body parts of male and female are given in Fig. 3 (a-n) while Pupa and mummy in Fig. 4 (o-r).

\section{Host stage preference}

The data on host stage preference in terms of parasitized host/female is presented in Table 3. Maximum mean number of parasitoid adults were emerged from adult (27) followed by $3^{\text {rd }}$ instar (22), $2^{\text {nd }}$ instar (10) and $1^{\text {st }}$ instar (0) (Fig. 1). Thus maximum percentage of parasitization of host occurred in adult host stage i.e. 90 per cent followed by $3^{\text {rd }}$, $2^{\text {nd }}$ and $1^{\text {st }}$ instar nymph with $73.33,33.33$ and 0 per cent, respectively. The linear regression equation is well fitted as $\mathrm{y}=31 \mathrm{x}-28.33$ and $\mathrm{R}^{2}=0.98$ (Fig. 2). It was found that $A e-$ nasius female laid increasingly more eggs with increasing host stage. Among the three nymphal stages $3^{\text {rd }}$ instar host stage was the most suitable and was desired host stage for mass rearing as it produced more progeny.

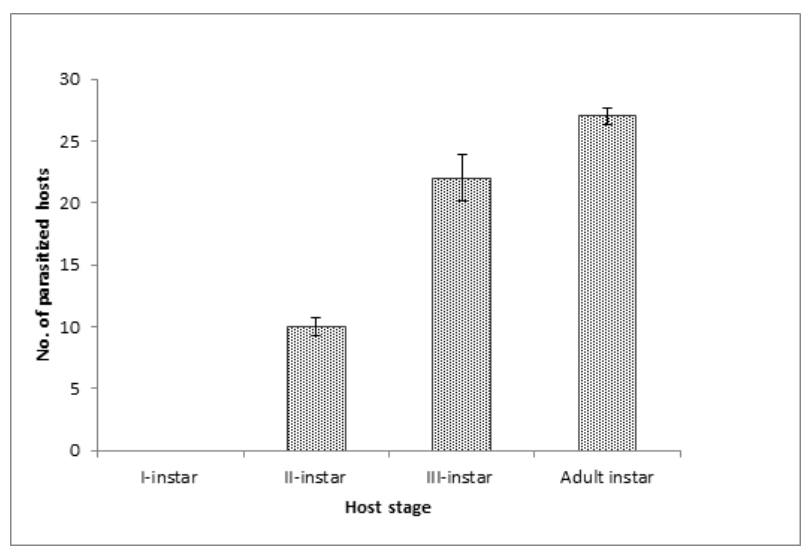

Fig. 1. No of parasitized host at different stages. (Error bars are corresponding Standard errors)

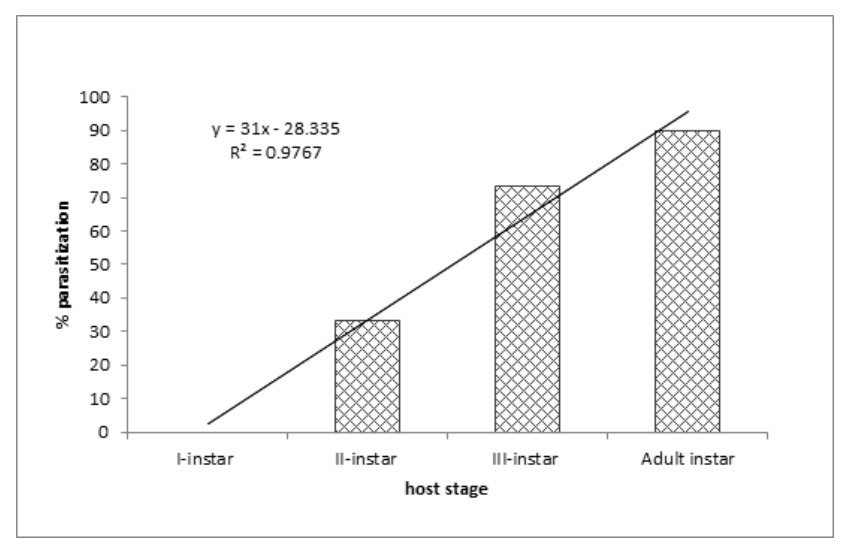

Fig. 2. Per cent parasitization of different host stages of Phenococcus solenopsis by Aenasius arizonensis. 


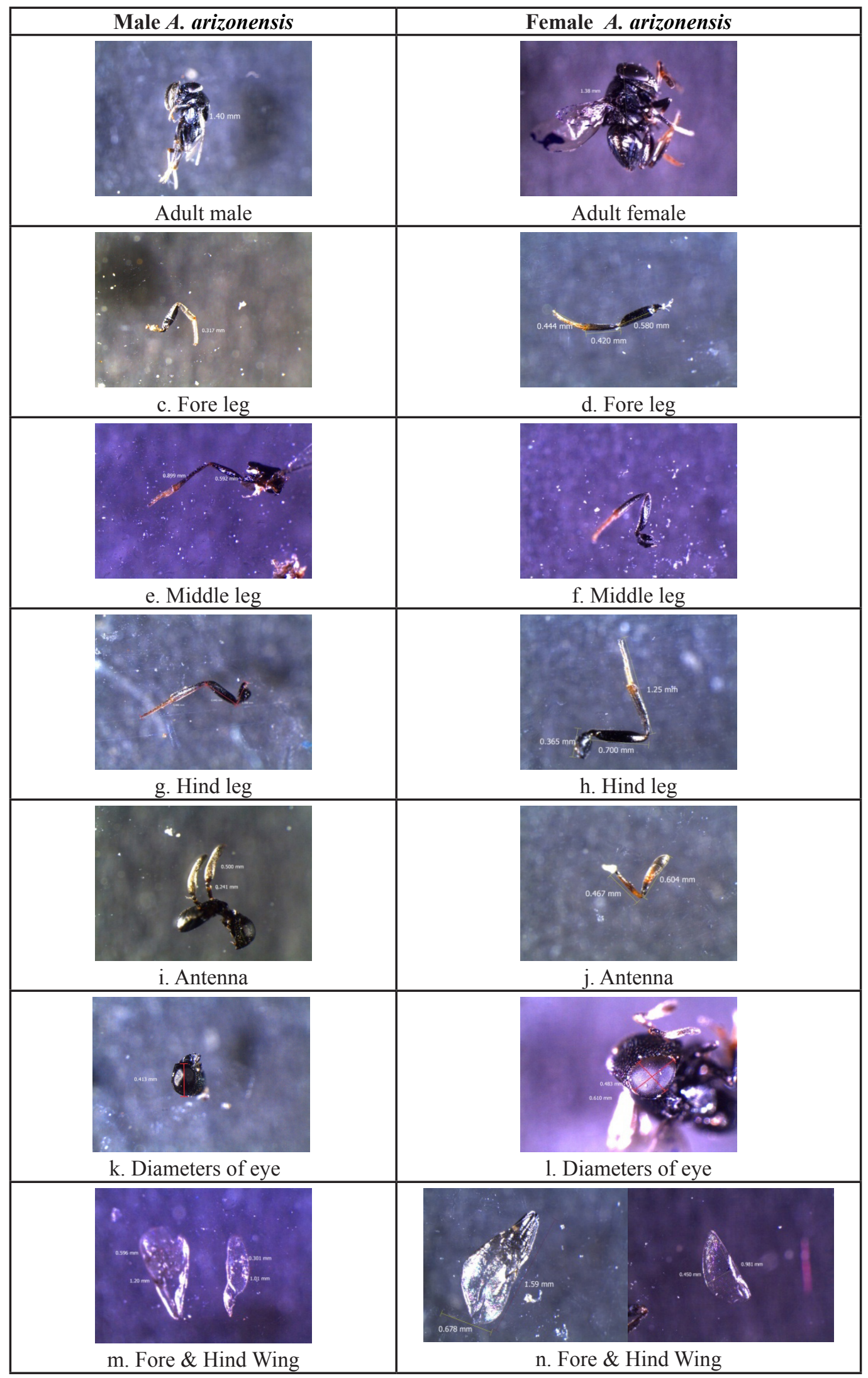

Fig. 3. Body parts Aenasius arizonensis male \& female. 


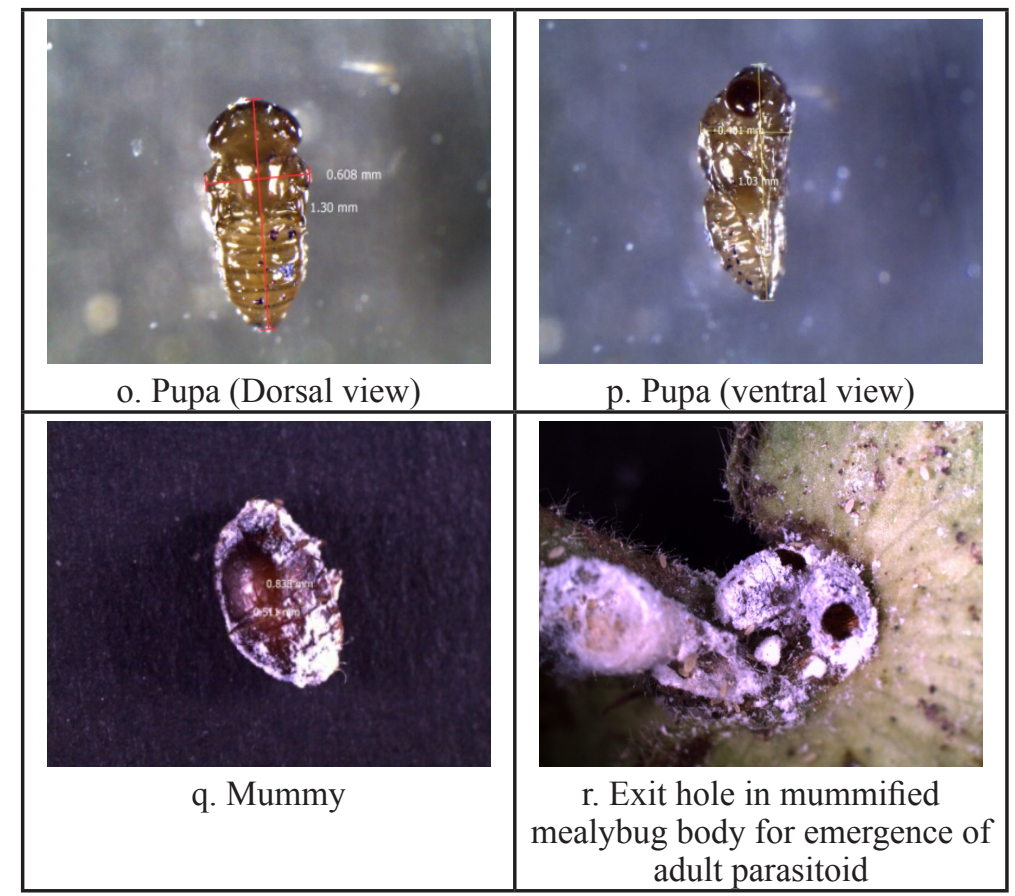

Fig. 4. Pupa and mummy of Aenasius arizonensis.

Aenasius arizonensis is one of the most potent biocontrol agents of solenopsis mealybug P. solenopsis. In the present study biology of the parasitoid has been studied where we found complete development of parasitoid takes place in 13-16 days from egg to adult emergence. About 5-8 days required for mummy formation and in almost all mummies an individual parasitoid emerged. Preoviposition period was $<1$ day while oviposition period ranged from 13-20 days. Sex ratio male: female in the progeny was recorded as 1:2 which is in close agreement with the reports of Abdin et al. (2013). Biological attributes reported herewith also in conformity with results of Vijaya et al. (2011). Most of the visual morphological measurements of male and female are in conformity with the previous reports (Hayat, 2009; Bodlah et al., 2010; Poorani et al., 2009). Results on the morphometrics of pupa can be related to studies by Sangle et al. (2013).

It was observed that female $A$. arizonensis laid eggs on all stages of cotton mealybug except first instar. This might be due to the small size of host and mobile in nature. As the development proceeded the emergence of $A$. arizonensis increased with maximum parasitization at adult stage $(90 \%)$ followed by $3^{\text {rd }}$ instar $(73.33 \%)$ and $2^{\text {nd }}$ instar $(33.33 \%)$. Among the three nymphal stages, $3^{\text {rd }}$ instar host stage is the most suitable and was desired host stage for mass rearing as it produced more progeny in this stage. Similar findings were also reported by Abdin et al. (2012). Many parasitoids, such as Anagyrus sp. nov.nr. sinope, aggressively select hosts of a specific age or size that have sufficient resources to produce progeny of a higher fitness (Chong and Oetting, 2006). Most of the parasitoids prefer adult mealybugs over nymphal stages as nymphal instars could have been less frequently encountered by the parasitoid due to their size and feeding site, as they remain in the axil of the leaves and feed there (Islam and Copland, 1997).

Linear relationship with host instars and per cent parasitization was observed. From the study it is clearly demonstrated that parasitoid preferred large host size containing adequate food sources to generate superior offsprings. Many studies suggest host size and development of progeny (Hayvey et al. 1994; Liu, 1985). Host preference tests showed that the mealybug parasitoid, Anagyrus pseudococci prefer older host instars that results in higher percentage emergence of parasitoid from older mealybugs (Islam and Copland, 1997). Our findings also supported by the reports of Strand and Casas (2008) where they revealed that parasitoid favors oviposition on larger, late-stage hosts, which suffer lower mortality rates and thus select for larger egg sizes and concomitantly lower fecundities. Our studies suggest that adult and third instar nymphs of $P$. solenopsis are highly preferred by $A$. arizonensis and can be an important host stage for mass multiplication of $A$. arizonensis.

\section{ACKNOWLEDGEMENT}

The authors thank Head, Crop Protection Division and Director, Central Institute for Cotton Research, Nagpur for providing research facilities. 


\section{REFERENCES}

Abdin ZHF, Khan MA, Abbas SK, Manzoor A, Shaina H. 2013. Reproductive fitness of mealybug parasitoid, Aenasius bambawalei Hayat (Hymenoptera: Encyrtidae). World Appl Sci J. 26(9): 1198-1203.

Abdin Z, Arif MJ, Gogi MD, Arshad M, Hussain F, Abbas SK, Shaina H, Manzoor A. 2012. Biological characteristics and host stage preference of mealybug parasitoid Aenasius bambawalei Hayat, (Hymenoptera: Encyrtidae). Pak Entomol., 34(1): 47-50.

Ahmed MZ, Ma J, Qiu BL, He RR, Wu MT, Liang F, Zhao JP, Lin L, Hu XN, Lv LH, Breinholt JW, Lu YY. 2015. Genetic record for a recent invasion of Phenacoccus solenopsis (Hemiptera: Pseudococcidae) in Asia. Environ Entomol. 44(3): 907-918. DOI: 10.1093/ee/ nvv034. Epub 2015 Mar 29.

Arif MI, Wazir S, Rafiq M, Ghaffar A, Mahmood R 2011. Incidence of Aenasius bambawalei Hayat on mealybug Phenacoccus solenopsis Tinsley and its hyperparasite, Promuscidea unfasciativentris Girault at Multan. Paper presented in 5th ICAC International Cotton Advisory Committee held at Lahore, Pakistan on February 23-25, 2011. http://www.icac.org/tis/ regional_networks/ asian_network/meeting_5/ documents/ papers / PapArifMI-et_al.pdf

Ashfaq M, Shah GS, Noor AR, Ansari SP, Mansoor S. 2010. Report of a parasitic wasp (Hymenoptera: Encyrtidae) parasitizing cotton mealybug (Hemiptera: Pseudococcidae) in Pakistan and use of PCR for estimating parasitism levels. Biocontrol Sci. Technol. 20, 625-630.

Bodlah I, Ahmad M, Faraq M, Naeem M. 2010. Record of Aenasisus bambawalei Hayat, a parasitoid of Phenacoccus solenopsis (Sternorrhynca: Pseudococcidae) from Panjab, Pakistan. Pakistan $J$ Zool. 42(5): 533-536.

CABI. 2015. Invasive species compendium datasheets, maps, images, abstracts and full text on invasive species of the world. Available from http://www.cabi. org/isc/datasheet/109097. (Accessed on $9^{\text {th }}$ February 2015).

Charnov EL, Hartogh RL Los-den, Jones WT, Van den Assem J. 1981. Sex ratio evolution in a variable environment. Nature 289: 27-33.

Chen HY, Cao RX, Xu ZF. 2010. First record of Aenasius bambawalei Hayat (Hymenoptera: Encyrtidae), a parasitoid of the mealybug, Phenacoccus solenopsis Tinsley (Hemiptera: Pseudococcidae) from China. $J$ Environ Entomol. 32: 280-282.

Chong JH, Oetting RD. 2006. Host stage selection of the mealybug parasitoid Anagyrus spec. nov.near sinope. Entomol Exp Appl. 121: 39-50.

Fallahzadeh M, Japoshvili G, Abdimaleki R, Saghaei N. 2014. New records of Tetracneminae (Hymenoptera, Chalcidoidea, Encyrtidae) from Iran. Turk $J$ Zool. 38. DOI: 10.3906/zoo-1309-28

Godfray HCJ. 1994. Parasitoids: Behavioral and evolutionary ecology. Princeton, New Jersey: Princeton University Press.

Harvey JA, Lem VET, Jiang N, Gols R. 1998. Nutritional ecology of the interaction between larvae of the gregarious ectoparasitoid, Muscidifurax raptorellus (Hymenoptera: Pteromalidae) and their pupal host, Musca domestica (Diptera: Muscidae). Physiol Entomol. 23: 113-120.

Hayat M. 2009. Description of a new species of Aenasius Walker (Hymenoptera: Encyrtidae), parasitoid of mealybug, Phenacoccus solenopsis Tinsley (Homoptera: Pseudococcidae). Biosystematica 3: $21-25$.

He XZ, Wang Q, Teulon DAJ. 2005. The effect of parasitism by Aphidius ervi on development and reproduction of the pea aphid, Acyrthosiphon pisum. New Zealand Pl. Protect., 58: 202-207.

Ignacimuthu S. 2002. Biological control of insect pests. $J$ Sci Ind Res. 61: 543-546.

Ignacimuthu S, Jayaraj S. 2003. Ecofriendly approaches for sustainable insect pest management. Curr Sci. 84: 1292-1293.

Islam KS, Copland MJW. 1997. Host Preference and progeny sex ratio in a solitary Koinobiont mealybug endoparasitoid, Anagyrus pseudococci (Girault), in response to its host stage. Biocontrol Sci Tech. 7: 449-456.

Lampson LJ, Morse JG, Luck RF. 1996. Host selection, sex allocation and host feeding by Metaphycus helvolus (Hymenoptera: Encyrtidae) on Saissetia oleae (Homoptera: Coccidae) and its effect on parasitoid size, sex and quality. Environ Entomol. 25: 283-294. 
Liu SS.1985. Development, adult size and fecundity of Aphidius sonchi reared in two instars of its aphid host, Hyperomyzus lactucae. Entomol Exp Appl. 37: 41-48.

Mahmood R. 2008. Breakthrough in biological control of mealybug in Pakistan. Biocontrol News Information 29, 38-39.

Mills NJ , Kuhlmanm U. 2000. The relationship between egg load and fecundity among Trichogramma parasitoids. Ecol Entomol. 25: 315-324.

Milonas PG. 2005. Influence of initial egg density and host size on the development of the gregarious parasitoid Bracon hebetor on three different host species. Biocontrol 50: 415-428.

Nagrare VS, Kranthi S, Kumar R, Dharajothi B, Amutha M, Deshmukh AJ, Bisane KD, Kranthi, KR. 2011. Compendium of cotton mealybugs. Technical Bulletin, Central Institute for Cotton Research, Nagpur. 42 pp.

Napoleon ME, King BH. 1999. Offspring sex ratio response to host size in the parasitoid wasp Spalangia endius. Behavioral Ecol Sociobiol. 46: 325-332.

Poorani J, Rajeshwari SK, Gupta A. 2009. Notes on diagnosis and biology of Aenasius bambawalei Hayat (Hymenoptera: Encyrtidae), a parasitoid of the invasive mealybug, Phenacoccus solenopsis Tinsley (Hemiptera: Pseudococcidae). J Biol Control 23: 463-466.

Ram P, Saini RK, Vijaya. 2009. Preliminary studies on field parasitisation and biology of solenopsis mealybug parasitoid Aenasius bambawalei Hayat, (Encyrtidae:Hymenoptera). J Cotton Res Dev. 23: 313-315.

Prasad YG, Prabhakar M, Sreedevi G, Thirupathi M. 2011. Spatio-temporal dynamics of the parasitoid, Aenasius bambawalei Hayat (Hymenoptera: Encyrtidae) on mealybug, Phenacoccus solenopsis Tinsley in cotton based cropping systems and associated weed flora. J Biol Control 25(3): 198-202.

Sangle PM, Korat DM, Patel BH. 2013. A note on morphometry and post larval life stages of Aenasius bambawalei Hayat. Karnataka J Agric Sci. 26: 151154.
Sequeira R, Mackauer M. 1993. The nutritional ecology of a parasitoid wasp, Ephedrus californicus Baker (Hymenoptera: Aphidiidae). Canadian Entomol. 125: 423-430.

Solangi GS, Mahmood R. 2011. Biology, host specificity and population trends of Aenasius bambawalei Hayat and its role controlling mealybug Phenacoccus solenopsis Tinsley a Tandojam Sindh. CABI South Asia, Tando Jam Pakistan.

Spargo G, Khan M, Byers K. 2013. A parasitoid of solenopsis mealybug found at Emerald. Australian Cottongrower. 34: 22-23.

Strand MR, Casas J. 2008. Parasitoid and host nutritional physiology in behavioral ecology, In Behavioral ecology of insect parasitoids: From theoretical approaches to field applications. Wiley Online. DOI: 10.1002/9780470696200.ch6

Vennila S, Prasad YG, Prabhakar M, Kumar Rishi, Nagrare V, Amutha M, Dharajyothi B, Agarwal M, Sreedevi G, Venkateswarlu B, Kranthi KR, Bambawale OM. 2011. Spatio-temporal distribution of host plants of cotton mealybug, Phenacoccus solenopsis Tinsley in India, Technical Bulletin No. 26, National Centre for Integrated Pest Management, New Delhi P 50.

Vijaya RP, Saini RK. 2011. Biology of Aenasius bambawlei Hayat (Hymenoptera: Encyrtidae). J Insect Sci. 24: 99-101.

Visser ME. 1994. The importance of being large: The relationship between size and fitness in females of the parasitoid Aphaereta minuta (Hymenoptera: Braconidae). J Animal Ecol. 63: 963-978.

Wang Y, Watson GW, Zhang R. 2010. The potential distribution of an invasive mealybug Phenacoccus solenopsis and its threat to cotton in Asia. Agric for Entomol. 12: 403-416.

Zaviezo T, Mills N. 2000. Factors influencing the evolution of clutch size in a gregarious insect parasitoid. J Animal Ecol. 69: 1047-1057. 